\title{
TECNOLOGÍAS DE LA INFORMACIÓN Y GEOGRAFÍA: USOS Y POTENCIALIDADES DE GOOGLE EARTH EN LAS PROPUESTAS DE ENSEÑANZA-APRENDIZAJE DE LA GEOGRAFÍA DESDE LOS PORTALES EDUCATIVOS.
}

\section{INFORMATION TECHNOLOGY AND GEOGRAPHY: USES AND POTENTIALITIES OF GOOGLE EARTH IN THE TEACHING AND LEARNING PROPOSALS OF GEOGRAPHY IN THE EDUCATION PORTALS}

\author{
Lic. Lucrecia Romina Díaz \\ Becaria CONICET \\ CIG-IGEHCS-CONICET \\ FCH-UNCPBA
}

\section{Resumen}

El presente trabajo tiene como objetivo analizar y discutir algunas cuestiones relacionadas al uso del recurso Google Earth como tecnología de visualización y representación del espacio, teniendo en cuenta sus herramientas y aplicaciones para trabajar en la enseñanza de la Geografía.

En torno a ello se pretende responder a los siguientes interrogantes: ¿Qué información brinda una imagen satelital de Google Earth y qué potencialidades presenta este recurso para estudiar el espacio a diferencia de recursos tradicionales? ¿Cuáles son los criterios por los cuáles dicha tecnología es incorporada en las propuestas de enseñanza-aprendizaje desde los portales educativos? ¿Qué temas y contenidos geográficos son posibles de abordarse desde esta tecnología? ¿Es posible producir una innovación en las prácticas de enseñanza-aprendizaje de la Geografía escolar a partir del uso de este recurso?

De este modo, intentaremos responder dichas preguntas a través de la discusión teórica de autores y el análisis de algunas fuentes de información (portales educativos de la Nación y Pcia. de Bs. As)

Palabras clave: Google Earth; propuestas de enseñanza-aprendizaje; Enseñanza de la Geografía; tecnologías de la información

\begin{abstract}
This work aims to analyze and discuss issues related to the use of Google Earth as a software technology of visualization and representation of space, by taking into account its tools and applications to work in the teaching of Geography.

Therefore, it is intended to answer the following questions: What information is provided by a satellite image of Google Earth and what potentialities does it offer to study space in contrast to traditional resources? What are the criteria by which this technology is incorporated into the teaching-learning proposals in educational websites? What topics and geographic contents can be addressed by using this technology? Is it possible to introduce an innovation in the teaching and learning practices of school Geography by making use of this resource?
\end{abstract}

These concerns will be the starting point to conduct this research in the following section.

Keywords: Google Earth; teaching-learning proposals; Geography; information technology 


\section{Sumario del artículo.}

$\checkmark$ Introducción

$\checkmark$ Aspectos metodológicos de la investigación.

$\checkmark$ Cambios en la cartografía digital: Google Earth y sus potencialidades como tecnología de visualización y representación del espacio

$\checkmark$ Implicancias del uso de Google Earth en la educación geográfica

$\checkmark$ Conclusiones

\section{Introducción}

En los últimos años es posible identificar una mayor circulación de imágenes de diferentes géneros (mapas, fotografías, videos, imágenes satelitales) a las cuales es posible acceder a través de la red de información y comunicación conocida como Internet. En lo que respecta a información de origen satelital es posible acceder a ellas a través de los atlas digitales como Google Earth, Google Map, Google Street, que junto a los SIG, han posibilitado el acceso a información diversa en tiempo real. En el caso de Google Earth es necesario destacar que su potencialidad como recurso tecnológico es la de permitir la visualización del espacio a través de la superposición de capas de información, la posibilidad de realizar itinerarios virtuales a partir de diferentes sentidos y ángulos y la asociación de esta tecnología con otros recursos (fotografías) y con otras tecnologías (you tube), lo que otorgan al mismo un gran potencial para comprender y estudiar diversos procesos espaciales.

A su vez, esta tecnología, ha cobrado notoriedad debido a sus potentes herramientas y ha sido incorporada en las propuestas de enseñanza-aprendizaje de diferentes portales educativos que sugieren su utilización en el aula, lo cual será analizado a continuación.

\section{Aspectos metodológicos de la investigación}

Esta investigación se llevó a cabo siguiendo una metodología cualitativa por medio de la cual se realizó una discusión teórica de autores que abordan el tema de investigación. A su vez, se realizó el análisis de fuentes de información durante el año 2012, lo cual que permite observar los criterios de selección de la tecnología Google Earth para la enseñanza de la Geografía en el diseño de propuestas de enseñanza-aprendizaje. Estas fuentes de información están constituidas por los portales educativos de la Nación y de la Pcia. de Bs. As: www.me.edu.ar, www.educ.ar, www.abc.gov.ar.

\section{Cambios en la cartografía digital: Google Earth y sus potencialidades como herramienta tecnológica de visualización y representación del espacio}

Numerosas discusiones se llevan a cabo en la actualidad acerca del uso de las nuevas tecnologías de la información y la comunicación vinculadas a la información satelital y la cartografía digital y sus posibles aplicaciones para el estudio de problemáticas espaciales, ambientales, sociales, entre otras. Tanto Google Earth, Google Map y otros atlas digitales de acceso a través de Internet han posibilitado la disponibilidad a información diversa (en este caso nos referimos a la información cartográfica) al alcance de cualquier usuario, ya no circunscripta a élites de mapeo, pues la producción de mapas y la de recolección de datos espaciales se fue yendo de las manos exclusivas de los expertos en las últimas décadas. La habilitación a la creación de mapas, incluso los interactivos mapas en 3D están ahora disponibles a diferentes usuarios a través de Internet. (Crampton, S/F). Cabe destacar que Internet ha posibilitado la mayor circulación de mapas, fotografía y otro tipo de imágenes. Es necesario destacar la importancia que adquieren en este contexto los sistemas de información

Publicado en formato digital: Lic. Lucrecia Romina Díaz. TECNOLOGÍAS DE LA INFORMACIÓN Y GEOGRAFíA: USOS Y POTENCIALIDADES DE GOOGLE EARTH EN LAS PROPUESTAS DE ENSEÑANZA-APRENDIZAJE DE LA GEOGRAFÍA DESDE LOS PORTALES EDUCATIVOS. Revista Geográfica Digital. IGUNNE. Facultad de Humanidades. UNNE. Año 10. No 20. Julio - Diciembre 2013. ISSN 1668-5180 Resistencia, Chaco. En: http://hum.unne.edu.ar/revistas/geoweb/default.htm 
geográfica (SIG) y las tecnologías de investigación geográfica, entre los cuales se anuncian cambios importantes como el crecimiento de datos de gran heterogeneidad y complejidad en tiempo real (real time data acquisition RTDA) y la cartografía en tiempo preciso (just in time mapping, JITM) junto a la aparición de ordenadores con pantallas táctiles que plantean la posibilidad de actuar sobre ellos con la voz (Capel, H, 2009).

En lo que respecta a Google Earth, podemos decir que el mismo, constituye un tipo de tecnología de visualización del espacio que presenta grandes potencialidades al momento de representar, visualizar y producir información sobre diferentes lugares del mundo. Esta tecnología, constituye una forma innovadora de representación de datos espaciales de gran heterogeneidad en tiempo casi real, pues la posibilidad de visualizar el espacio a través de la superposición de capas de información, la articulación con el recurso Google Maps, y su vinculación con sitios como You Tube y Wikipedia permite articular texto, imagen y sonido a la vez. La posibilidad de realizar itinerarios virtuales a partir de diferentes sentidos y ángulos le otorgan al mismo un gran potencial para comprender y estudiar el espacio debido a sus rasgos de interactividad que distinguen la producción de imágenes satelitales de este soporte de los mapas convencionales de la cartografía tradicional.

Hace unas décadas, la información espacial contenida en los mapas y atlas se realizó en base a una tradicional representación cartográfica de la realidad en forma plana y bidimensional producida en manos de expertos, en la actualidad la emergencia de nuevas herramientas cartográficas produjeron un cambio en la forma de representar, visualizar y producir nueva información espacial en forma dinámica y versátil lo que permite la interacción del usuario con la tecnología.

Si hacemos referencia a las herramientas y aplicaciones que presenta Google Earth como tecnología de visualización, es necesario hacer hincapié en la posibilidad de realizar recorridos virtuales desde diferentes ángulos y posiciones y en diferentes escalas de análisis, la superposición de capas de información referida a calles, rutas, edificios, la posibilidad de calcular distancias y establecer coordenadas de localización de lugares. A su vez, permite la búsqueda de localizaciones concretas, como locales comerciales, restaurantes, entidades bancarias; así como también visualizar áreas de las ciudades referidas a la localización de ciertos servicios: turísticos, inmobiliarios, de entretenimiento; por lo que se vincula al recurso Google Earth con el geomarketing. Coincidiendo con Metternicht, G (2006); las potencialidades de esta tecnología estriban además en la posibilidad de contar con información actualizada para monitorear áreas afectadas por catástrofes naturales (volcanes), problemáticas ambientales (disminución de casquetes polares) como así también visualizar procesos de planificación urbana. (Metternicht, G; 2006)

Como se mencionó anteriormente, esta tecnología permite su articulación con otros sitios de Internet a través de hipervínculos (you tube, wikipedia) así como también su relación con otros recursos: imágenes y texto. La aplicación Google Maps permite la participación del usuario, quien tiene la posibilidad de confeccionar sus propios mapas temáticos.

Por eso otras de las potencialidades de el soporte Google Earth estriba en que permite un mayor acceso a los mapas y a los debates sobre el uso de los mismos, mayores niveles de interactividad de los usuarios, sobre todo de aquellos no profesionales que pueden participar de las actividades de mapeo. A su vez, existe una red social creada en torno a Google Earth "Google Earth Community", en la que se publican marcas de posición donde se las relaciona con información accesible a cualquier usuario. (Farman, 2010). Por otro lado, Farman, (2010) discute las implicancias culturales de esta tecnología, ya que si bien considera que la misma permite un acceso más participativo de los mapas, marca la existencia de una cartografía digital del imperio a la vez que se pregunta sobre el tipo de colonialismo que podría estar presente en la aparentemente "neutral" tecnología de Google Earth.

Publicado en formato digital: Lic. Lucrecia Romina Díaz. TECNOLOGíAS DE LA INFORMACIÓN Y GEOGRAFÍA: USOS Y POTENCIALIDADES DE GOOGLE EARTH EN LAS PROPUESTAS DE ENSEÑANZA-APRENDIZAJE DE LA GEOGRAFÍA DESDE LOS PORTALES EDUCATIVOS. Revista Geográfica Digital. IGUNNE. Facultad de Humanidades. UNNE. Año 10. No 20. Julio - Diciembre 2013. ISSN 1668-5180 Resistencia, Chaco. En: http://hum.unne.edu.ar/revistas/geoweb/default.htm 
Respecto del tipo de imágenes que permite visualizar este soporte, podemos decir que las mismas permiten realizar una lectura sobre el espacio que depende de la mirada o perspectiva desde donde nos posicionamos. Pues, "la lectura del espacio es de hecho una 'lectura', una entre otras, interpretación que nunca es fuera de la cultura que produjo tal lectura" (Farman, J; 2010:466). Por lo tanto, al utilizar el soporte Google Earth para visualizar diversos aspectos de la realidad, cabe preguntarse en qué objetos o fenómenos particulares centramos nuestra visión, pues qué es lo que observamos y miramos, y cómo lo hacemos, es decir, cuál es la mirada que realizamos de los fenómenos y desde qué enfoque o perspectiva lo hacemos, teniendo en cuenta que lo que observamos, en gran parte está condicionado por nuestras ideas, nuestros valores e intereses y nuestros sentimientos. A lo que observamos le otorgamos un sentido y un significado, pues entra en juego nuestra subjetividad. A su vez, aquello que observamos cobra sentido según el contexto histórico, social, político y cultural en el que vivimos, lo que le otorga un significado y un contenido particular. Por eso es que la producción de mapas no es neutra ni objetiva y mucho menos su interpretación sobre diferentes procesos espaciales.

Imágen Nº: Pantalla inicial del software Google Earth con la imagen de la Tierra.

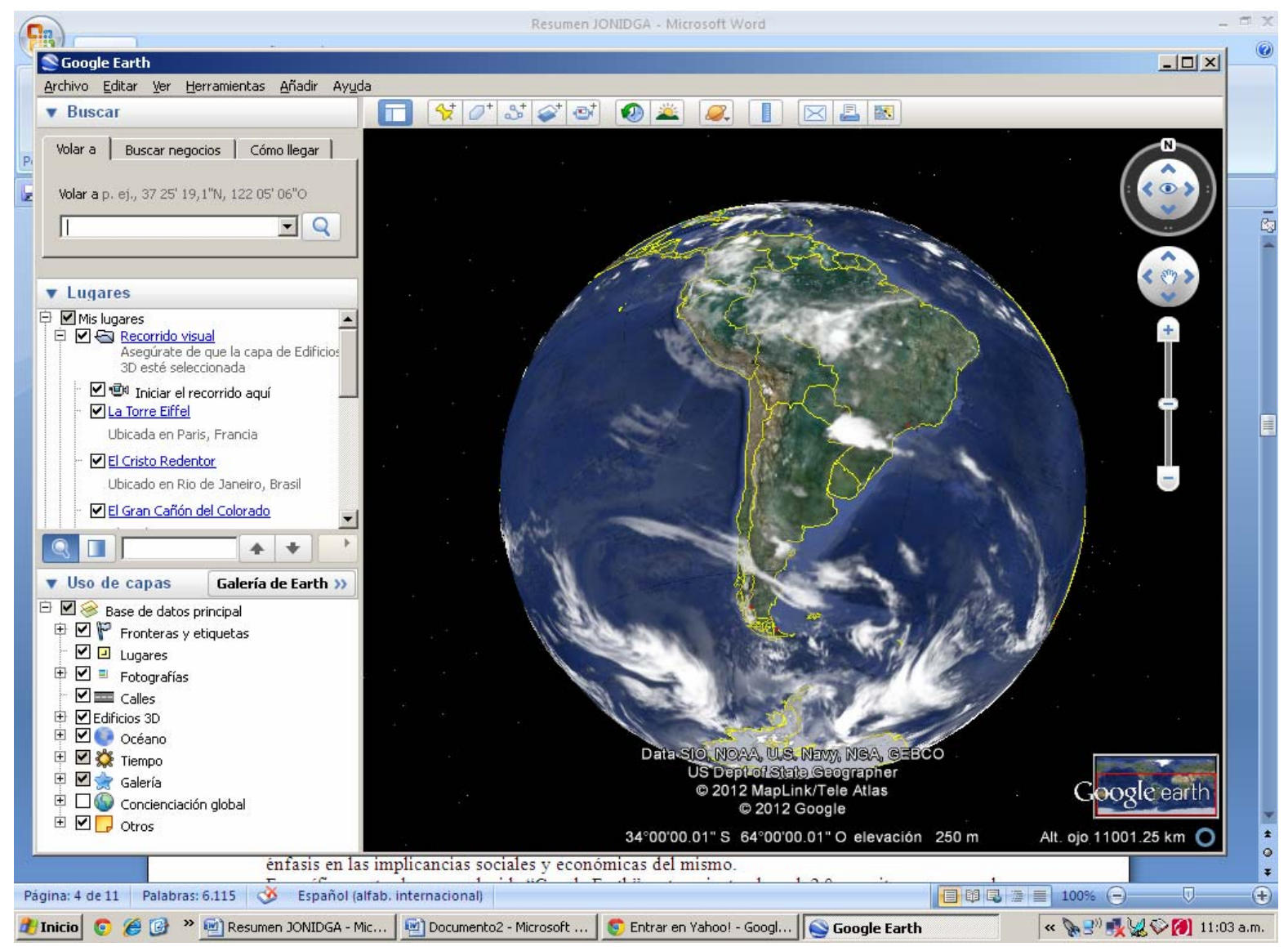

Fuente: Google Earth (2012). Díaz, L. Captura de pantalla. 


\section{Implicancias del uso de Google Earth en la educación geográfica}

En los últimos años, una gran cantidad y variedad de información satelital accesible a través de Internet se incorpora para trabajar en la escuela para el abordaje de diversos contenidos de la enseñanza. Si bien Google Earth no posee un fin educativo en sí mismo sus herramientas y potencialidades permiten su aplicación para incorporarlo en el proceso de enseñanza y aprendizaje dentro del aula. Pues este recurso constituye un tipo de cartografía digital interesante debido a su carácter dinámico e interactivo que permite la participación de los alumnos en la producción de materiales cartográficos para el monitoreo y análisis de temas geográficos: problemas ambientales, planificación urbana, desastres naturales, entre otros. Si entendemos que "Las propuestas innovadoras son ideas y proyectos que se materializan en objetos, en construcciones, en soportes diversos y dependen de condiciones de producción, históricas y tecnológicas para expresarse" [...] (Gurevich, 2005:1) el uso de Google Earth es pertinente para el trabajo de Geografía en el aula, puesto que promueve el aprendizaje significativo y colaborativo por parte de los alumnos. Ya que las profundas transformaciones socio-territoriales producidas hoy a nivel global plantean una nueva forma de renovar los marcos teóricos y metodológicos de la Geografía, se debe pensar desde luego, en nuevas estrategias de enseñanza y aprendizaje que superen el método tradicional basado en el aprendizaje memorístico y repetitivo cuyo objetivo es describir fenómenos físicos considerando al espacio como un "soporte" o "escenario". Hoy, la Geografía se inscribe dentro de una perspectiva crítica y renovada que intenta explicar y reflexionar sobre las relaciones entre la sociedad y la naturaleza, pensando en una sociedad conformada por sujetos activos y participativos, por lo tanto el espacio geográfico lejos de ser un soporte de fenómenos físicos, se constituye como un producto social en permanente cambio.

Específicamente el recurso elegido, "Google Earth" perteneciente a la web 2.0, posee una diversidad de herramientas que permite que los estudiantes construyan diversos productos cartográficos, y comprueben la veracidad de los datos que le han sido suministrados llevándolos a la práctica; en otras palabras, los mismos pueden interactuar con el conocimiento y hacerlo trascender a diferentes ámbitos, aprehenderlo y producirlo. En este sentido, las problemáticas geográficas y los contenidos comprendidos dentro del Diseño curricular de la Geografía pueden explorarse, abordarse y estudiarse a partir de una tecnología como Google Earth. Sin embargo, es preciso tener en cuenta que las potencialidades del recurso y las innovaciones que el mismo pueda proponer no dependen del soporte en sí mismo, sino del uso adecuado de estrategias metodológicas, de las propuestas de actividades, de los objetivos pedagógicos y didácticos que se persigan, en fin del diseño de propuestas de enseñanza y aprendizaje que se propongan, considerando a los alumnos como sujetos de conocimiento.

Teniendo en cuenta los aspectos didácticos, metodológicos y pedagógicos que permiten la incorporación de una tecnología como Google Earth, el uso de imágenes satelitales en Geografía pueden constituir una herramienta potente para la enseñanza.

Podemos decir que los criterios y objetivos de implementación de estas tecnologías en el aula guardan relación con el hecho de considerar a las tecnologías de la información y la comunicación y sobre todo en este caso, a las imágenes satelitales como un recurso valioso para la enseñanza. Podemos resumir aquí sus potencialidades para la enseñanza a partir de estos puntos se señalados por Zapettini, C; (2007):

$\checkmark$ Proveen de información clave para la enseñanza que no puede ser adquirida a través de otros recursos.

Publicado en formato digital: Lic. Lucrecia Romina Díaz. TECNOLOGÍAS DE LA INFORMACIÓN Y GEOGRAFÍA: USOS Y POTENCIALIDADES DE GOOGLE EARTH EN LAS PROPUESTAS DE ENSEÑANZA-APRENDIZAJE DE LA GEOGRAFÍA DESDE LOS PORTALES EDUCATIVOS. Revista Geográfica Digital. IGUNNE. Facultad de Humanidades. UNNE. Año 10. No 20. Julio - Diciembre 2013. ISSN 1668-5180 Resistencia, Chaco. En: http://hum.unne.edu.ar/revistas/geoweb/default.htm 
$\checkmark \quad$ La observación, lectura y análisis de este tipo de imágenes constituyen otras formas de acceder, representar y construir el conocimiento.

$\checkmark$ Permite abordar el estudio de diversas problemáticas desde su complejidad: a través de diversas escalas de análisis, identificando posibles causas de los problemas y actores que intervienen en la misma.

$\checkmark$ Favorecen el desarrollo de capacidades como la percepción y otras formas de representación. Pues, no reemplazan otras formas de representación pero las complementan.

$\checkmark$ Ponen en juego diversas estrategias de interpretación y visualización.

$\checkmark$ Propone otras formas de visualización alternativas a la cartografía tradicional a través de múltiples escalas y superposición de capas de visualización.

$\checkmark$ Genera nuevas habilidades de lectura, comprensión y análisis de información geo-referenciada.

$\checkmark$ Permite relacionar información espacial con una base de datos.

$\checkmark$ Permite la realización de mapas temáticos con información buscada y analizada por los propios alumnos.

$\checkmark$ Posibilita la articulación entre imagen, texto y sonido.

$\checkmark$ Facilita el acceso a información no accesible a través de otros recursos.

Imagen N²: Visualización de un problema geográfico con el software Google Earth. (La erupción del Volcán Puyehue en Chile)

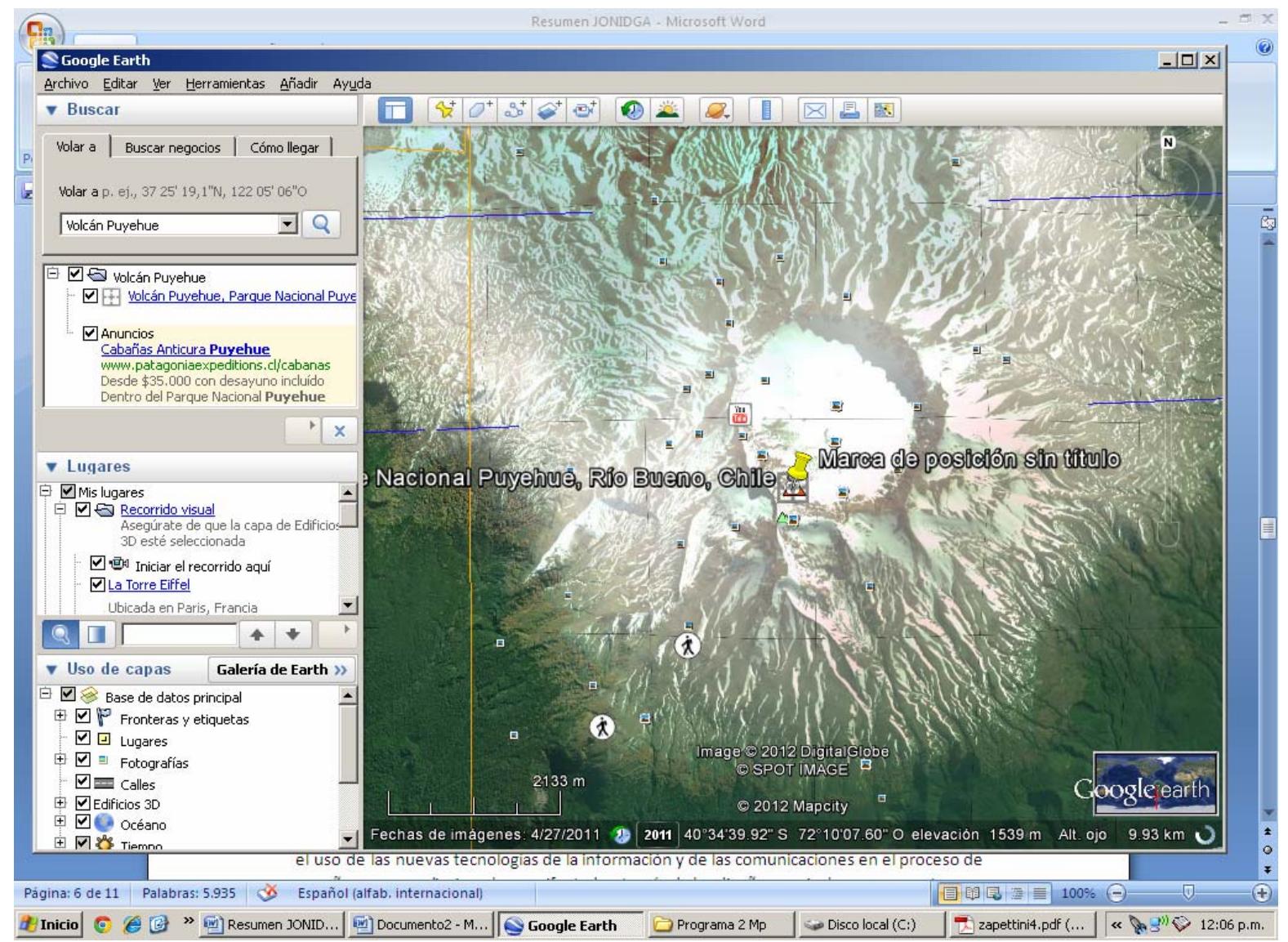

Fuente: Google Earth (2012), Díaz, L. Captura de pantalla. 
Revista Geográfica Digital. IGUNNE. Facultad de Humanidades. UNNE. Año 10. № 20.

Julio - Diciembre 2013. ISSN 1668-5180 Resistencia, Chaco

Imagen N³: Visualización del Volcán a partir de Google Maps con la incorporación de fotografías.

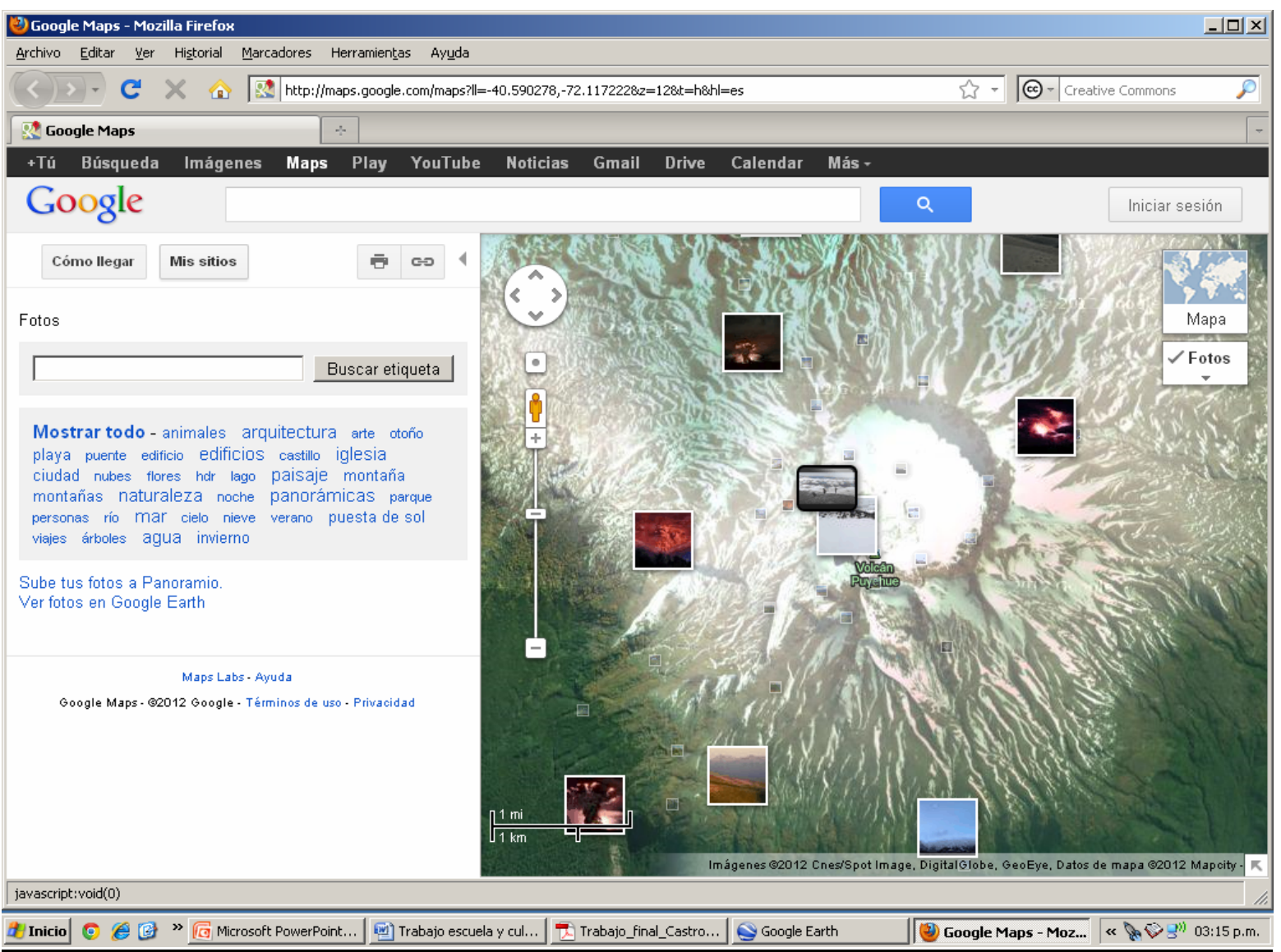

Fuente: Google Earth (2012), Díaz, L. Captura de pantalla. 
Imagen N4: Visualización del Volcán en Google Maps a partir de la incorporación de fotografías y de enlaces con el sitio Wikipedia.

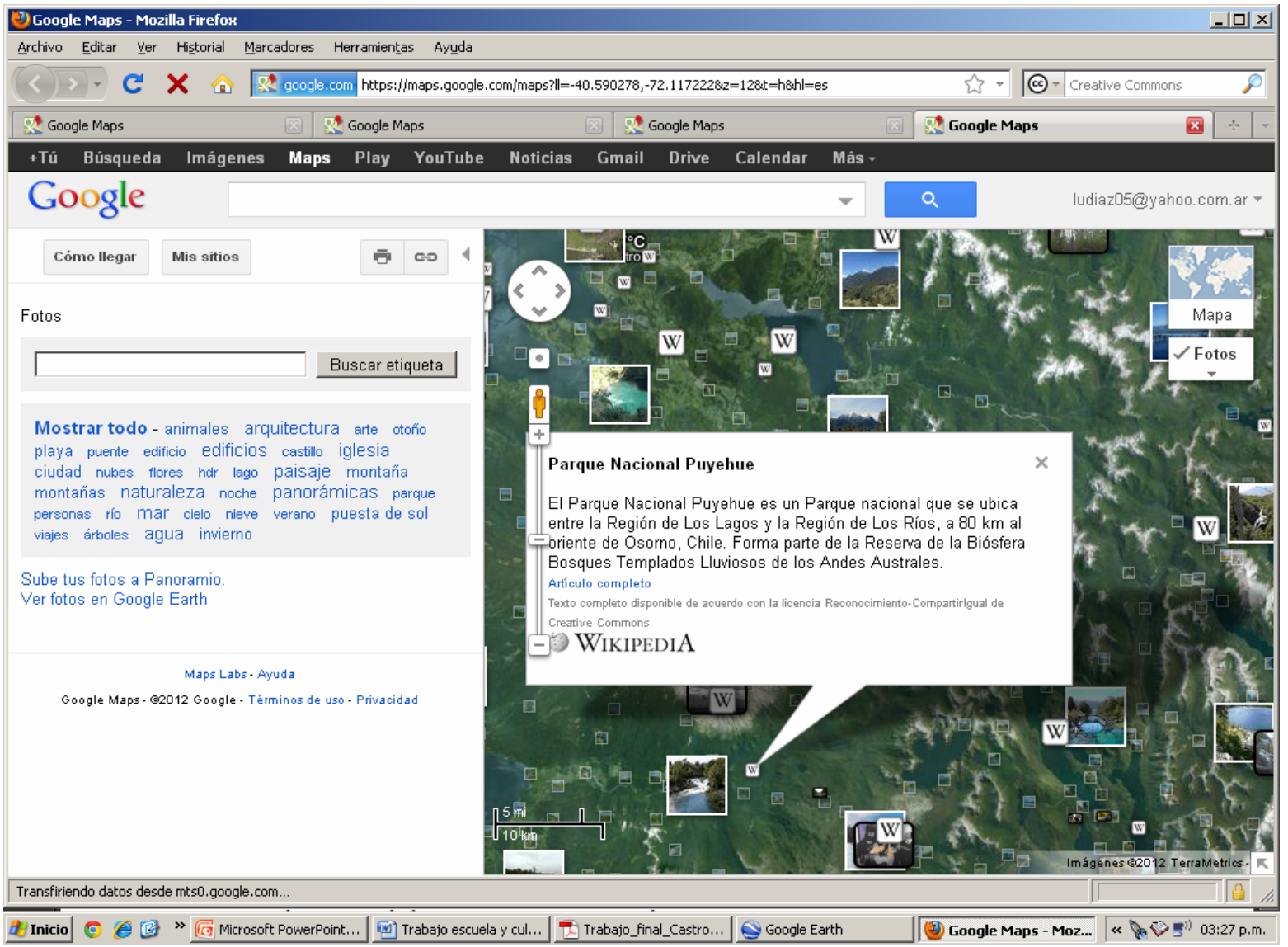

Fuente: Google Earth (2012), Díaz, L. Captura de pantalla.

Respecto de la utilización de Google Earth para trabajar en el aula es pertinente observar que "recientemente se han definido dos modelos de actividades geointeractivas: Earthquest ${ }^{1} \mathrm{y}$ Geoquest. ${ }^{2}$ Ambas propuestas se inspiran en las webquest, adaptándolas al contexto cognitivo del espacio geográfico y tecnológico de herramientas como Google Maps, Google Earth, Virtual Earth o WorldWind" [...]. "Una Earthquest es una actividad geointeractiva, que se basa en las funcionalidades de la aplicación Google Earth y tiene una organización formal estructurada en una serie de tarea" (Luque Revuelto, 2011:204), ello permite seleccionar un caso de estudio y trabajarlo teniendo en cuenta la incorporación de objetivos didácticos específicos, las categorías que serán trabajadas y actividades, integrándolas en una secuencia didáctica que luego se trabajará con los alumnos a

\footnotetext{
${ }^{1}$ Esta propuesta fue diseñada por los profesores holandeses John Demmers y Gerard Dümmer en el año 2005.

${ }^{2}$ Propuesto por G.T. Kalsbeek de la Universidad de Amsterdam y de J.J.J.M. Beenakker del C.M. Kan-Instituut (Vivancos, J; 2006)
}

Publicado en formato digital: Lic. Lucrecia Romina Díaz. TECNOLOGÍAS DE LA INFORMACIÓN Y GEOGRAFÍA: USOS Y POTENCIALIDADES DE GOOGLE EARTH EN LAS PROPUESTAS DE ENSEÑANZA-APRENDIZAJE DE LA GEOGRAFÍA DESDE LOS PORTALES EDUCATIVOS. Revista Geográfica Digital. IGUNNE. Facultad de Humanidades. UNNE. Año 10. No 20. Julio - Diciembre 2013. ISSN 1668-5180 Resistencia, Chaco. En: http://hum.unne.edu.ar/revistas/geoweb/default.htm 
través de la web. Este tipo de actividades posibilita la selección, interpretación y procesamiento de los datos disponibles a través del software. Una de las propuestas de Earthquest fue inspirada en la obra de Julio Verne "La vuelta al mundo en 80 días". la misma fue creada por Gómez, J ("La volta al món en 80 dies"y readaptada por Vivancos, J (2006) "La vuelta al mundo en 80 minutos" ${ }^{3}$, a la cual se puede acceder mediante el siguiente link: (http://www.xtec.net/ jvivanco/80minuts/80minutos.htm).

Para el caso de los Geoquest también se selecciona un caso de análisis, se establecen objetivos de enseñanza- aprendizaje y se plantean tareas y preguntas a resolver por los alumnos. Sin embargo "a diferencia de las Earthquest, las Geoquest no se basan necesariamente en un software interactivo específico. Es suficiente una página web para definir y presentar la actividad". (Vivancos, J; 2006:4). Son numerosas las aplicaciones del software Google Earth para la realización de propuestas para la enseñanza de la Geografía. A pesar de sus limitaciones y potencialidades el recurso Google Earth se ha convertido en una herramienta para el estudio de procesos geográficos que demandan nuevas formas de enseñanza- aprendizaje y nuevas estrategias.

En Argentina, la incorporación de recursos tecnológicos de este tipo en el Diseño Curricular de la Geografía, así como el hecho de ocupar un lugar destacado dentro de los objetivos de enseñanza y aprendizaje y las unidades didácticas de la asignatura manifiestan la importancia que se les otorga a estas tecnologías para trabajar en el estudio de problemática ambientales (cambio climático, contaminación de agua y suelos) y problemáticas sociales (pobreza, segregación y fragmentación socio-territorial), teniendo en cuenta los contenidos de la asignatura para cada año de la educación secundaria y su forma de enseñarlos.

En consonancia con lo dicho anteriormente, en lo que se refiere al uso de las tecnologías de la información y la comunicación (TIC) tecnologías en la geografía escolar, podemos decir que "los nuevos desarrollos teórico-metodológicos de la geografía y de la didáctica justifican la necesidad de renovar tanto los conocimientos como las maneras de enseñarlos. Es decir, nuevos contenidos que resultan significativos para entender la realidad social y que, al mismo tiempo, generen en los alumnos actitudes críticas y creativas comprometidas con su medio sociocultural." (Ochoa, M; 2006). Esta necesidad de renovarse plantea a su vez la necesidad de implementar diversos recursos en el proceso de enseñanza-aprendizaje, los cuales plantean como novedad la posibilidad de mirar y reflexionar de forma diferente la compleja realidad que nos toca vivir. La necesidad de renovar y reflexionar acerca de los contenidos de la geografía que incluyan el uso de las nuevas tecnologías de la información y de las comunicaciones en el proceso de enseñanza-aprendizaje se ha manifestado a través de los diseños curriculares propuestos por el Ministerio de Educación de la Nación, (a través del Programa Conectar Igualdad) que tienen en cuenta la incorporación de las TIC para trabajar con los contenidos curriculares de la asignatura en el aula.

A continuación se presentan aquí algunos fragmentos que hacen referencia a la incorporación de las TIC, específicamente en lo que respecta al uso de cartografía temática satelital y digital en la

\footnotetext{
${ }^{3}$ Esta actividad consiste en un viaje por el espacio y el tiempo en una duración de 80 minutos desde diferentes alturas y ángulos de observación en las que se van intercalando imágenes de diferentes períodos históricos hasta la actualidad. Entre los principales objetivos de la actividad se pretende: "Promover la lectura e interpretación de imágenes satélite, aprender los conceptos de coordenadas geográficas de forma significativa, realizar medidas y cálculos sobre imágenes satélite, con herramientas interactivas, estimular las competencias de búsqueda de información textual y gráfica" (Vivancos, J; 2006:2).
} 
Geografía en el Nivel Secundario, teniendo en cuenta la organización de contenidos curriculares del área de Ciencias Sociales perteneciente a la Dirección General de Cultura y Educación de la Pcia. de Bs. As; incluidos en su respectivo Portal de Internet (www.abc.gov.ar), lo que denota la importancia y estímulo dado por las políticas educativas impulsadas por el Estado para propiciar el uso de este tipo de tecnologías en el aula.

Diseño Curricular para $2^{\circ}$ año (SB) | Ciencias Sociales: Algunas consideraciones didácticas.

Acompañar a los alumnos/as en el uso de herramientas de las nuevas tecnologías para que desarrollen habilidades y capacidades de un acceso crítico a la información que se puedan encontrar a partir de su uso. Internet resulta, probablemente, el máximo exponente de las Nuevas Tecnologías y uno de los espacios virtuales en los que se puede encontrar la información más actualizada sobre la producción de conocimientos sociales y específicamente geográficos. Es necesario acompañar a los alumnos/as en la exploración del mundo virtual, facilitarles directrices básicas sobre qué, dónde y cómo moverse por la red. Por ejemplo, el acercamiento a muchos sitios de imágenes virtuales y fotografías aéreas sobre la superficie de la tierra, acompañadas de necesarias reflexiones, contribuye a construir una mirada y percepción diferente del espacio geográfico que, inevitablemente, logra activar la imaginación geográfica y las representaciones de los alumnos/as.

\section{Diseño Curricular para la Educación Secundaria Ciclo Superior 4to año}

\section{Objetivos de enseñanza}

$\checkmark \quad$ Incorporar con distintos grados de complejidad la enseñanza de la materia a través de las Nuevas Tecnologías de Información y Conectividad (NTlyCx) a los fines de que las mismas sean utilizadas para el desarrollo de preguntas, formulación y tratamiento de problemas, así como para la obtención, procesamiento y comunicación de la información generada.

$\checkmark \quad$ Promover el trabajo con la más diversa variedad de mapas (topográficos, temáticos u otros) utilizando la riqueza de sus elementos cartográficos y las interpretaciones que se puedan hacer de ellos para llegar a expresar mediante los mismos el desarrollo y las conclusiones de sus informes $y / 0$ investigaciones escolares.

\section{Objetivos de aprendizaje}

$\checkmark \quad$ Indagar en el conocimiento geográfico, de tal modo que pueda desarrollar mayores y mejores saberes en relación con el manejo de la información escrita, estadística y gráfica, así como las que corresponden a las Nuevas Tecnologías de la Información y la Conectividad (NTlyCx) aplicadas a la disciplina Sistemas de Información Geográfica (SIG).

\section{Consideraciones para la enseñanza de los contenidos de $3^{\circ}$ año}

$\checkmark \quad$ Enriquecer los estudios de caso y otras estrategias de enseñanza con el aporte de diversidad de soportes visuales como es el caso de las fotografías aéreas, las imágenes satelitales u otros recursos similares para el abordaje de problemas geográficos. Las imágenes satelitales y las 
fotografías aéreas, por ejemplo, ofrecen visiones de conjunto con una información que enriquecen las del mapa o el plano.

Los objetivos de enseñanza-aprendizaje que se plantean en estos fragmentos manifiestan el imperativo de implementar las diferentes producciones cartográficas (mapas, imágenes satelitales) en la enseñanza de la Geografía. En el caso de las imágenes satelitales, podemos decir que constituyen otras formas de representación que posibilitan el tratamiento de temas complejos y relevantes en la geografía actual que no reemplazan a la cartografía tradicional sino que la complementan y potencian para trabajar en el aula.

Por otro lado, se puede observar la incorporación de las imágenes satelitales del soporte Google Earth en portales educativos como www.educ.ar y www.me.gov.ar. A partir del programa Conectar Igualdad, se lo incorpora como material educativo en la lista de software educativo que contienen las netbooks, a través del "Maletín del Docente" y en el "Maletín del alumno" donde se incorpora esta tecnología para trabajar en la clase. Otra forma de circulación de material pertinente a esta tecnología es la producción de revistas y libros específicos desde el Ministerio de Educación de la Nación para cada asignatura de la enseñanza secundaria que contienen información relevante para trabajar con estas tecnologías, una de ellas es específicamente dirigida al uso de Google Earth en las clases de Geografía.

En el libro de actividades específico sobre Google Earth, producido desde el Ministerio de Educación de la Nación se argumenta la importancia de esta TIC para explicar 1) La Dimensión planetaria: Coordenadas geográficas, movimientos de rotación, husos horarios, etc.; 2)- Localización, ubicación y el trabajo en distintas escalas geográficas; 3) Las características de los paisajes y los elementos del relieve; 4) La morfología de los espacios urbanos: Allí se incorporan imágenes satelitales sobre diversos lugares del planeta y sobre ciudades disponibles a través de la web.

Por otro lado, se sugieren algunos sitios específicos para trabajar en el aula sobre cuatro temáticas distintas cada una con su sitio web en el que es posible acceder a propuestas y sugerencias para trabajar en el aula.

$\checkmark$ Sobre Espacio urbano:

http://coleccion.educ.ar/coleccion/CD17/contenidos/ppea/geografia/vazquez.html

$\checkmark \quad$ Un viaje virtual hacia las regiones argentinas:

http://coleccion.educ.ar/coleccion/CD17/contenidos/ppea/geografia/martinez.html

$\checkmark$ Trabajando con escalas en representaciones cartográficas:

http://coleccion.educ.ar/coleccion/CD17/contenidos/ppea/geografia/almara.htmlhttp://www.educ. ar/edcaur/site/educar/trabajando-con-escalas-en-representaciones-cartográficas.html

$\checkmark$ Sobre Geografía continental:

http://escritoriodocentes.educ.ar/datos/Geografia continental.html

Asimismo se sugiere el uso del software Google Maps en el que los alumnos pueden confeccionar sus propios mapas según los diversos temas de interés que estén estudiando y compartirlos a través de la web con su docente y compañeros. 
Así es que esta herramienta para trabajar en el aula es difundida y promovida por diferentes portales educativos que sugieren su uso a través del diseño de secuencias didácticas.

Como se mencionó anteriormente, en el Portal del Ministerio de Educación de la Nación, en lo que se refiere al Programa "Conectar Igualdad", aparecen algunas propuestas metodológicas para los docentes de Educación Secundaria de la Provincia de Buenos Aires. Estas propuestas, que conforman lo que se denomina el "Maletín del Docente" se estructuran en: Secuencias, Recorridos, Actividades, Biblioteca, Videos, Programas y Software educativo.

A continuación se describen algunas de estas propuestas para trabajar en Geografía tomando en cuenta aquellas que consideran específicamente a la tecnología Google Earth y la vinculan con algunos contenidos temáticos de la asignatura.

En la sección Secuencias se puede observar una serie de propuestas para trabajar en el aula, las cuales dos de ellas apuntan específicamente al uso de Google Earth. La primera se denomina "Introducción al concepto de geolocalización e instalación del software Google Earth", orientado a la localización de objetos espaciales y la búsqueda de información a partir de coordenadas geográficas a través de la base de datos que ofrecen los sistemas de información geográfica; la segunda propuesta titulada: "Google Earth y Google Maps, generando mapas y archivos KML, KMZ" donde se enseña a crear mapas temáticos en los formatos mencionados para luego compartirlos a través de la web. Ambas secuencias sugieren un conjunto de actividades para que los docentes puedan seleccionar al momento de planificar una clase para trabajar con los alumnos en el uso del recurso al que hacemos referencia. Ambas actividades tienen como objetivos en común promover el trabajo colaborativo en red y la discusión e intercambio entre pares, así como también estimular la búsqueda, selección crítica e interpretación de la información proveniente de diversos soportes.

Con respecto a los Recorridos de aprendizaje en Geografía, aparece una propuesta denominada "Vacaciones en mi pueblo o en mi barrio" en la que se pretende que los alumnos puedan evaluar el potencial turístico del lugar donde viven. La idea es que los alumnos realicen un recorrido visual de su lugar de residencia y puedan seleccionar algunos puntos vinculados a la infraestructura: restaurantes, hoteles, parques y otros lugares de esparcimiento, así como otro tipo de información de interés: centros de salud, comisaría, centros de información, entre otros. Otro de los recorridos titulado "La minería en la Argentina" pretende que los alumnos identifiquen y analicen los casos más controversiales que surgen de esta actividad y los actores sociales en conflicto. En este caso, como en el anterior se promueve el uso del soporte Google Earth complementado con otro tipo de información proveniente de diversos soportes.

En la sección Programas y Software educativo, Google Earth aparece como el único software del área de Ciencias Sociales. En este mismo bloque no solo se puede descargar el programa, sino que se puede acceder a un tutorial o guía de uso del mismo.

En el apartado Videos aparecen breves presentaciones sobre temas específicos. Uno titulado ¿Urbano o rural? Periurbano, el segundo denominado: Productores periurbanos. Las actividades productivas periurbanas y el tercero llamado Mancha urbana: La expansión geográfica del AMBA. Estos tres videos muy breves incluyen el uso del recurso que es aquí motivo de estudio y que puede ser complementado con la utilización de otras tecnologías y otros recursos didácticos. 
A continuación se analiza brevemente una Secuencia Didáctica denominada: Geografía de la República Argentina. Características económicas y sociales de países del Mercosur. En ella se proponen los mismos objetivos generales que en las anteriores secuencias: Fomentar el intercambio entre alumnos y estimular la búsqueda, selección crítica e interpretación de la información por parte de los alumnos a través de la utilización de equipos portátiles (netbooks) en las clases de Geografía.

Respecto de los objetivos de las actividades propuestas, los mismos consisten en la localización física y geográfica de nuestro país, su situación y límites del territorio dentro del continente americano; el reconocimiento de las actividades económicas del país y las relaciones del mismo en el mercado regional e internacional; por último que los alumnos realicen recorridos dentro del país y calculen distancias estableciendo diferentes caminos e itinerarios.

Con respecto a las actividades planteadas aparecen cinco propuestas que responden a ejes temáticos diversos.

> La primera actividad denominada "Límites del Territorio Nacional" apunta principalmente a visualizar e identificar algunos aspectos del territorio de nuestro país: la ubicación geográfica (según las coordenadas geográficas) y delimitación del territorio según aspectos físicos (relieve, hidrografía). En la misma se incluyen imágenes que muestran a modo de ejemplo y de guía cómo realizar los recorridos por el territorio y cómo ubicar algunos puntos que identifican ciudades importantes, como por ejemplo la ciudad capital de nuestro país.

$>$ La segunda actividad: "Identificación de pasos fronterizos y ciudades de frontera sobre el mapa de Argentina" se propone la identificación de áreas de frontera del territorio argentino, la división política de la Nación según las diferentes provincias que la componen y la localización de las ciudades capitales de cada una de ellas. Se pretende a su vez, la incorporación de recursos como fotografías o videos representativos y característicos de algunas ciudades. Los mapas creados pueden ser subidos a un blog o wiki para ser compartidos a través de la web con otras personas.

$>$ La tercera actividad: Regiones Naturales Argentinas. Tiene como objetivo registrar las regiones naturales del país teniendo en cuenta aspectos físicos como el relieve, clima, biomas, zonas de desastres naturales (zonas sísmicas, por ejemplo), Sector antártico e islas Australes. Además se debe realizar una búsqueda de información sobre la Guerra de Malvinas y la situación actual sobre el reclamo por las islas por parte de los países en conflicto e información sobre la caza de ballenas en el sur del país y la legislación de protección ambiental.

> La cuarta actividad denominada Actividad Económica Nacional pone énfasis en el relevamiento de áreas vinculadas a los sectores económicos: agrícola-ganadero, industrial y de servicios, y en las rutas de comercio nacional e internacional. Aquí se complementa el uso del soporte Google Earth con Google Docs y se promueve la publicación de los productos realizados en un blog o wiki para ser compartidos.

> La quinta actividad Inmigración e integración cultural se propone indagar sobre los cambios demográficos ocurridos en el país a partir de la llegada de diversos grupos migratorios y de la emigración de argentinos a diferentes partes del mundo en períodos de crisis económicas y de cambios de diversa índole. Las producciones realizadas a partir de esta actividad también articulan como en el caso anterior el trabajo colaborativo en Google Earth con Google Docs y Slideshare. 
Luego de la breve descripción de cada una de las actividades propuestas en la secuencia sugerida, podemos decir que las mismas apuntan a cinco áreas temáticas diferentes: tres referidas al área física o natural, una relacionada al área económica y la última orientada al área social y cultural, lo cual fragmenta los contenidos de la asignatura e impide el análisis de ciertos temas geográficos en forma integral y como totalidad. Las estrategias metodológicas y las actividades propuestas se circunscriben a la localización e identificación de elementos o puntos y análisis de flujos de intercambios entre nuestro país y el mundo pero no se observa el análisis de procesos geográficos en su complejidad, teniendo en cuenta las diversas escalas de análisis: mundo, región y lugar. Resultaría interesante incorporar como estrategia metodológica una problematización o estudio de caso sobre un tema en particular, pues el análisis de una problemática geográfica posibilita el abordaje de las tres áreas temáticas abordadas: física o natural, económica y social-cultural, lo que implica considerar un problema desde su complejidad, teniendo en cuenta las múltiples dimensiones que explican la problemática. A su vez, es necesario tener en cuenta por un lado la compleja relación sociedadnaturaleza y el rol de los actores sociales que intervienen en la problemática estudiada desde sus diversos intereses, ideas y acciones. Por último, resulta interesante destacar la importancia de señalar objetivos didácticos, metodológicos y pedagógicos específicos de las actividades propuestas teniendo en cuenta los destinatarios de la secuencia didáctica planteada. Por lo tanto, las potencialidades del recurso Google Earth cobran sentido según el tipo de secuencia didáctica que se diseñe para trabajar en el aula, lo cual va más allá de las herramientas y aplicaciones que este soporte nos pueda proveer.

\section{Conclusiones}

Para finalizar este trabajo, cabe decir que si bien la tecnología Google Earth presenta grandes potencialidades como herramienta para trabajar en la Geografía escolar, el hecho de que este recurso no sea educativo hace necesario que los docentes seleccionen su utilización y aplicación para trabajar en el aula teniendo en cuenta diversos aspectos: objetivos pedagógicos, metodológicos y didácticos y estrategias de enseñanza-aprendizaje propias de la disciplina, pues las herramientas que este software pueda proveer no dependen de cuestiones puramente técnicas sino de las decisiones que se tomen en relación a le selección de los contenidos con que se va a trabajar, categorías geográficas seleccionadas y los objetivos y estrategias expresadas anteriormente. Coincidiendo con Litwin "El soporte que brinda la tecnología es pasible, pues, de reconocerse como enmarcando una propuesta, limitándola o expandiéndola según el tipo de tratamiento que posibilita y la manera de utilización de parte del docente para el desarrollo de las comprensiones" (Litwin, E; 2005:19). De este modo, las innovaciones educativas que se pueden llevar a cabo en el aula, guardan relación no solo con la incorporación de este tipo de soportes sino de nuevas prácticas de enseñanza-aprendizaje que permitan al alumno ser partícipes de esa innovación. 
Referencias citadas

$\checkmark$ Capel, H. 2009. "La enseñanza digital, los campus virtuales y la geografía" en: revista electrónica de recursos en internet sobre geografía y ciencias sociales. universidad de Barcelona $\mathrm{n}^{\circ}$ 125. ISSN: 1578-0007. Barcelona

$\checkmark$ Crampton, J; Krygier J. S/F. "an introduction to critical cartography". acme: an international ejournal for critical geographies, 4 (1), (11-33).

$\checkmark$ Dussel, I. (2009). "Escuela y cultura de la imagen: Los nuevos desafíos", en: Revista Nómadas, No. 30, Abril 2009, pp. 180-193.

$\checkmark$ Dussel, I; Quevedo, L .2010. "Educación y nuevas tecnologías: los desafíos pedagógicos ante el mundo digital" en: VI Foro Latinoamericano de Educación. Educación y Nuevas tecnologías: los desafíos pedagógicos ante el mundo digital. Documento básico. Fundación Santillana.

$\checkmark$ Dussel, I; Quevedo, L .2010. "Aprender y enseñar en la era digital" en VII Foro Latinoamericano de Educación. Experiencias y aplicaciones en el aula. Aprender y enseñar con nuevas tecnologías. Fundación Santillana.

$\checkmark$ Farman, J .2011. "Google earth and the process of postmodern cartography" en: Dodge, m; Kitchin, $r$; Perkins, Ch (comps.) the map reader: theories of mapping practices and cartographic representation. Ed. Wiley. 504 pp.

$\checkmark$ Gurevich .2005. "Innovaciones educativas y práctica docente en Geografía" en: Una introducción a la enseñanza de las sociedades y territorios en tiempos contemporáneos. Ed. Fondo de Cultura económica. pp.124

$\checkmark \quad$ Litwin, E .2005. (Comp.) “Tecnologías educativas en tiempo de Internet”. Amorrortu Editores. Bs. As. pp.13-34.

$\checkmark \quad$ Luque Revuelto, R .2011. "El uso de la cartografía y la imagen digital como recurso didáctico en la enseñanza secundaria. Algunas precisiones en torno a Google Earth". Boletín de la Asociación de Geógrafos españoles, №55. Pp. 183-210.

$\checkmark$ Metternicht, G. 2006.: "Consideraciones acerca del impacto de Google Earth en la valoración y difusión de los productos de georrepresentación", geofocus (editorial), no 6, p.1-10, ISSN: 1578-5157

$\checkmark$ Ochoa, M (2006) “Cambios en la enseñanza de la Geografía” en: www.educ.ar, Portal educativo del Estado argentino. Bs. As.

Vivancos. 2006. "Earthquest y Geoquest: dos propuestas de actividades Geointeractivas" en: Comunicación a las Primeras Jornadas sobre Webquest. Barcelona 10-11 de Marzo 2006

$\checkmark$ Zapettini, MC. 2007. "Enseñanza de la Geografía e Informática: el uso del SIG en una experiencia pedagógica innovadora" en: Revista Geograficando. Revista del Departamento de Geografía de la UNLP. Año 3 №3. pp. 189-203.

Portales educativos de Internet

www.me.gov.ar

www.educ.ar.gov.ar

www.abc.gov.ar

Enlaces de sitios web (Secuencias didácticas)

http://secuencias.educ. ar/mod/resource/view.php?id=4845

http://secuencias.educ.ar/mod/resource/view.php?id=4848

http://www.educ.ar/dinamico/UnidadHtml get 91ef98e8-c848-11e0-81f1-e7f760fda940/index.htm

Publicado en formato digital: Lic. Lucrecia Romina Díaz. TECNOLOGÍAS DE LA INFORMACIÓN Y GEOGRAFÍA: USOS Y POTENCIALIDADES DE GOOGLE EARTH EN LAS PROPUESTAS DE ENSEÑANZA-APRENDIZAJE DE LA GEOGRAFÍA DESDE LOS PORTALES EDUCATIVOS. Revista Geográfica Digital. IGUNNE. Facultad de Humanidades. UNNE. Año 10. No 20. Julio - Diciembre 2013. ISSN 1668-5180 Resistencia, Chaco. En: http://hum.unne.edu.ar/revistas/geoweb/default.htm 
Revista Geográfica Digital. IGUNNE. Facultad de Humanidades. UNNE. Año 10. № 20.

Julio - Diciembre 2013. ISSN 1668-5180 Resistencia, Chaco

\section{Videos}

http://videos.educ.ar/play/Disciplinas/ Geografia/Productores periurbanos (Galería multimedia videos)

http://escritoriodocentes.educ.ar/datos/g5periurbano.html (Videos)

http://videos.educ.ar/play/Disciplinas/ Geografia/Mancha urbana (Galería multimedia videos) 